\title{
Chapter 2 \\ Complex Systems Theories and Eclectic Approach in Analysing and Theorising the Contemporary International Security Complex
}

\author{
Luis Tomé \\ University Autónoma of Lisbon, Portugal
}

\begin{abstract}
This chapter has a dual purpose: first, it is intended to demonstrate the need and usefulness of Complex systems theories and, in this context, what we call an "Eclectic Approach" for analysing and theorising about International Relations and security; second, it aims to characterise the contemporary international security system. We also develop two basic arguments: that the reality is too complex, heterogeneous and varied to fit into theories that purport to interpret exclusively in the light of its previous cognitive structures; and that the contemporary international security system is a complex of international security systems - competitive, cooperative, collective, and security communities.
\end{abstract}

\section{INTRODUCTION}

The conceptualisation of "security" and the "international security system" are two of the most discussed and controversial issues in the entire theoretical area of International Relations. One of the few consensual aspects of these discussions is the "dynamic" and "complex" character of security and the international security system. It is surprising, therefore, that to theorise about these realities, many insist on not using or even rejecting more pluralist and flexible approaches, opting instead for inflexible paradigms and restricted in their assumptions, variables and propositions. However, the evident complexity of international relations and security, as well as the shortcomings of conventional and traditionally prominent theories, require alternative proposals. 
This chapter has a dual purpose: first, it is intended to demonstrate the need and usefulness of Complex systems theories and, in this context, what we call an "Eclectic Approach" for analysing and theorising about International Relations and security; second, it aims to characterise the current international security system, which proves to be a complex of security systems.

These objectives are developed on the basis of two fundamental arguments. We consider that reality is too complex, heterogeneous and varied to fit into theories that purport to interpret exclusively in the light of its previous abstractions, built on certain foundational assumptions and adapted to all situations regardless of specific circumstances and evolutions. It is our argument that none of the conventional theories, including prominent paradigms such as Realism, Liberalism and Constructivism, provide analytical and explanatory frameworks that meet all the complexities of international politics and security. In light of developments and changes in the field of security and the international system, we argument that the contemporary international security system is a complex of international security systems.

\section{Limitations of Traditional International Relations Theories}

In an effort to understand and explain behaviours and international interactions, diverse theorising has invoked a particular vocabulary that adheres to specific concepts, adopts a specific analytical framework and develops a set of its own explanatory hypotheses. On the basis of several conceptions and explanations, there are cognitive structures that take the theoretical currents and thinkers to perceive and to emphasise different aspects. Customarily, observers and scientists in International Relations and Security Studies refer to these structures as "theories" - although some prefer the word "paradigms" following the thesis of Thomas Kuhn (1962), others opt for the concept of "research programme" of Imre Lakatos (1970) and others still for the notion of "research tradition" by Larry Laudan (1996).

Regardless of the preferred terminology, which begins by distinguishing the various "fields" long before the theoretical explanations they produce, are the cognitive structures on which the respective formulations are based. These cognitive structures indicate that aspects are considered important and explainable, that concepts and methods are employed and which parameters are used to draw conclusions. Theoretical beliefs crystallise around certain basic assumptions, forming a specific "theory" or "paradigm". Most academics and analysts therefore think of the theoretical universe as being divided between different "theories" adapted to any context and all situations. This is particularly evident in the debates that opposed the various "theories of International Relations", competing with one another about which presents the most appropriate interpretation. In the end, as referred to by Tony Smith (1994: 350), "each paradigm is monotheistic, praying to a jealous God."

The point is that traditional IRs theories tend to discuss and select only those aspects of the international politics that are in keeping with their cognitive structures and their "natural expectations". This means that, as a rule, IRs theories including Realism, Liberalism, and Constructivism make secondary or simply do not involve elements and variables that can be absolutely crucial to understand and explain a highly diverse and complex reality. Similarly, to the extent that conventional theories are, as a rule, inflexible in their postulates, they transpose conceptions to new contexts that might, nevertheless, already be outdated and/or in need of reformulation. In addition, the set of formulations embodied in a given theory, once institutionalised with their weaknesses and inconsistencies tend to make them no longer recognised by the respective proponents, their key assumptions no longer questioned and their "anomalies" persistently overlooked or considered to hold little relevance. Consequently, some theorising can 
12 more pages are available in the full version of this document, which may be purchased using the "Add to Cart" button on the product's webpage: www.igi-global.com/chapter/complex-systems-theories-and-eclecticapproach-in-analysing-and-theorising-the-contemporary-internationalsecurity-complex/150408?camid=4v1

This title is available in Advances in Religious and Cultural Studies, InfoSciBooks, Communications, Social Science, and Healthcare, InfoSci-Social Sciences and Humanities, InfoSci-Select, InfoSci-Social Sciences Collection. Recommend this product to your librarian: www.igi-global.com/e-resources/library-recommendation/?id=115

\section{Related Content}

Basic Concepts of Internet of Things and Game Theory

(2017). Game Theory Solutions for the Internet of Things: Emerging Research and Opportunities (pp. 112).

www.igi-global.com/chapter/basic-concepts-of-internet-of-things-and-gametheory/175161 ?camid $=4 \mathrm{v} 1 \mathrm{a}$

A Boolean Logic Approach to Issues of Vagueness, Heuristics, Subjectivity, and Data Mining: A Boolean Logic, 0-1, Approach

Russell Jay Hendel (2018). Philosophical Perceptions on Logic and Order (pp. 196-217). www.igi-global.com/chapter/a-boolean-logic-approach-to-issues-of-vagueness-heuristicssubjectivity-and-data-mining/182210?camid=4v1a

Understanding Entrepreneurship through Chaos and Complexity Perspectives Wassim J. Aloulou (2016). Handbook of Research on Chaos and Complexity Theory in the Social Sciences (pp. 195-212).

www.igi-global.com/chapter/understanding-entrepreneurship-through-chaos-and-complexityperspectives $/ 150421$ ?camid $=4 \mathrm{v} 1 \mathrm{a}$

Foreign Aid to Africa: Conceptualising Socio-Economic and Political Development Applying Complexity Theory

Sultan Juma Kakuba (2016). Handbook of Research on Chaos and Complexity Theory in the Social Sciences (pp. 114-124).

www.igi-global.com/chapter/foreign-aid-to-africa/150415?camid=4v1a 